\title{
$\beta$-thymosins and interstitial lung disease: study of a scleroderma cohort with a one-year follow-up
}

\author{
Maria De Santis ${ }^{1}$, Rosanna Inzitari ${ }^{2}$, Silvia L Bosello ${ }^{1}$, Giusy Peluso ${ }^{1}$, Chiara Fanali ${ }^{2}$, Federica lavarone ${ }^{2}$, \\ Gaetano Zizzo ${ }^{1}$, Mario Bocci', Tiziana Cabras ${ }^{3}$, Irene Messana ${ }^{3}$, Leo Fuso ${ }^{4}$, Francesco Varone ${ }^{4}$, Gabriella Pagliari ${ }^{4}$, \\ Massimo Castagnola 2,5 , Gianfranco Ferraccioli ${ }^{1 *}$
}

\begin{abstract}
Background: $\beta$-thymosins play roles in cytoskeleton rearrangement, angiogenesis, fibrosis and reparative process, thus suggesting a possible involvement in the pathogenesis of systemic sclerosis. The aim of the study was to investigate the presence of thymosins $\beta_{4}, \beta_{4}$ sulfoxide, and $\beta_{10}$ in bronchoalveolar lavage fluid of scleroderma patients with interstitial lung disease and the relation of these factors with pulmonary functional and radiological parameters.

Methods: $\beta$-thymosins concentrations were determined by Reverse Phase-High Performance Liquid Chromatography-Electrospray-Mass Spectrometry in the bronchoalveolar lavage fluid of 46 scleroderma patients with lung involvement and of 15 controls.

Results: Thymosin $\beta_{4}, \beta_{4}$ sulfoxide, and $\beta_{10}$ were detectable in bronchoalveolar lavage fluid of patients and controls. Thymosin $\beta_{4}$ levels were significantly higher in scleroderma patients than in controls. In addition, analyzing the progression of scleroderma lung disease at one-year follow-up, we have found that higher thymosin $\beta_{4}$ levels seem to have a protective role against lung tissue damage. Thymosin $\beta_{4}$ sulfoxide levels were higher in the smokers and in the scleroderma patients with alveolitis.

Conclusions: We describe for the first time $\beta$-thymosins in bronchoalveolar lavage fluid and their possible involvement in the pathogenesis of scleroderma lung disease. Thymosin $\beta_{4}$ seems to have a protective role against lung tissue damage, while its oxidation product mirrors an alveolar inflammatory status.
\end{abstract}

\section{Background}

$\beta$-thymosins are a family of G-actin sequestering peptides involved in cytoskeleton rearrangement, intracellular signaling, cell-cell adhesion, motility, survival, differentiation, and malignant transformation [1]. While in mammalian tissues thymosin $\beta_{4}$ is usually the main peptide, representing about $70-80 \%$ of the total $\beta$-thymosins content [2], thymosin $\beta_{10}$ is usually detectable at concentrations about 5-10-fold lower compared to thymosin $\beta_{4}$. However, in preneoplastic and neoplastic tissues and in activated lymphocytes the ratio thymosin $\beta_{10} / \beta_{4}$ seems to increase $[3,4]$. The oxidation product of thymosin $\beta_{4}$ at the Methionine ${ }_{6}$ residue, thymosin $\beta_{4}$ sulfoxide, was also detectable in many body fluids [5].

\footnotetext{
* Correspondence: gf.ferraccioli@rm.unicatt.it

${ }^{1}$ Department of Rheumatology, Catholic University, Rome, Italy

Full list of author information is available at the end of the article
}

Although the secretion pathway is not fully understood, recent studies highlighted various extra-cellular roles for these peptides [1]. Thymosin $\beta_{4}$ is essential for platelet-clot formation and wound healing [6]. Moreover, while thymosin $\beta_{10}$ seems to have anti-angiogenic properties, significantly decreasing mRNA levels of vascular endothelial growth factor (VEGF) and of VEGF receptor-1, thymosin $\beta_{4}$ promotes angiogenesis $[7,8]$. Of interest thymosin $\beta_{4}$ can up-regulate the expression of hepatocyte growth factor and down-regulate the expression of platelet derived growth factor-beta receptor in a model of liver fibrosis, thus suggesting an anti-fibrotic potential role of thymosin $\beta_{4}$ [9]. Furthermore, both thy$\operatorname{mosin} \beta_{4}$ and thymosin $\beta_{4}$ sulfoxide seem to have antiinflammatory properties $[10,11]$.

The role of $\beta$-thymosins in cytoskeleton rearrangement, angiogenesis, fibrosis and reparative process

\section{() Biomed Central}


suggests a possible involvement of these peptides in the pathogenesis of systemic sclerosis, a multi-organ connective tissue disease characterized by skin and internal organ fibrosis and microvascular abnormalities. The cytokines and paracrine factors underlying fibrosis and vasculopathy in scleroderma are not completely characterized yet.

The presence of thymosin $\beta_{4}$ and thymosin $\beta_{10}$ in body fluids, such as saliva, has been recently demonstrated using a number of immunological [12] and proteomic [5] techniques, but not in bronchoalveolar lavage fluid (BALF). Therefore, the present study has been carried out with the aim to demonstrate the presence of $\beta$-thymosins in BALF of normal subjects and of scleroderma patients with interstitial lung disease and to correlate their levels with the biologic, functional and radiological parameters of lung involvement, through Reverse Phase-High Performance Liquid Chromatography-Electrospray-Mass Spectrometry analysis (RPHPLC-ESI-MS) of the naturally occurring peptides.

In this study we have described for the first time $\beta$-thymosins in human BALF. Moreover, we have hypothesized a possible involvement of these factors in the pathogenesis of scleroderma lung disease. In fact, we have found higher concentrations of thymosin $\beta 4$ in the BALF of scleroderma patients with lung involvement compared to the normal counterpart and of thymosin $\beta 4$ sulfoxide in the subset of scleroderma patients with alveolitis. In addition, analyzing the progression of scleroderma lung disease at one-year follow-up, we have found that higher thymosin $\beta_{4}$ levels seem to have a protective role against lung tissue damage.

\section{Methods}

\section{Scleroderma patients}

46 scleroderma patients with evidence of interstitial lung disease on high resolution computed tomography (HRCT) (reticular pattern and/or ground glass or honeycombing), consecutively admitted to the outpatient clinic of the Rheumatology Division of the Catholic University in Rome from January 2007 to December 2009, consenting to undergo bronchoalveolar lavage, have been included in the study. All the patients have fulfilled the criteria proposed by the American College of Rheumatology [13] and have been classified in limited and diffuse subset according to LeRoy classification [14]. ANA (antinuclear antibodies) have been determined by indirect immunofluorescence using Hep 2 cells as substrates and autoantibody specificities were assessed by enzyme-linked immunosorbent assay (ELISA) [15]. Demographic, clinical and lung involvement characteristics of the patients are summarized in the table 1 .

The study is conform to the recommendations of the Declaration of Helsinki and the study protocol has been approved by the local ethical committee. An informed written consent has been obtained from the patients.

\section{Control subjects}

As controls we have used the BALF from 15 subjects who performed the exam for a solitary pulmonary nodule, either in the lobe with the nodule or in the contro-lateral normal lobe, after obtaining an informed written consent. BALF cytological and microbiological exams have been all negative. Controls' mean age has been $60.0 \pm 12.0$ years, females have been $9(60.0 \%)$, smokers have been 3 (20.0\%).

\section{Study design}

We have investigated through RP-HPLC-ESI-MS the presence of $\beta$-thymosins in the BALF of 46 scleroderma patients with interstitial lung disease and 15 normal subjects, and we have studied the correlations between BALF $\beta$-thymosin levels and the biologic, functional and radiological parameters of scleroderma lung involvement and of its progression. All the enrolled patients have performed pulmonary function tests, echocardiography, HRCT of the lung within one month before performing bronchoalveolar lavage. Pulmonary function tests and HRCT have been repeated after a one-year follow-up.

\section{Pulmonary function tests}

Pulmonary function tests have been performed to define forced vital capacity (FVC) and carbon monoxide diffusing capacity (DLCO), as described elsewhere [16,17]. FVC $<80 \%$ with normal forced expiratory volume in one second/FVC has been defined as restrictive lung disease [16]. A decrease in FVC $>10 \%$ and in DLCO $>15 \%$ at one-year follow-up has been considered a clinically significant variation $[18,19]$.

\section{Echocardiography}

Pulmonary artery systolic pressure has been calculated with the simplified Bernoulli equation [15]. High pulmonary arterial pressure (HPAP) has been defined as pulmonary artery systolic pressure $>35 \mathrm{mmHg}$ [20].

\section{HRCT score system}

HRCT has been performed as described elsewhere [15]. Two independent readers have scored ground glass opacity (alveolar score) and honeycombing (honeycombing score) on a scale of 0-5 in the three lobes of both lungs, as described elsewhere [15]. An increase in alveolar or honeycombing score $>1$ point at one-year follow-up has been considered clinically significant.

\section{Bronchoalveolar lavage analysis}

Bronchoalveolar lavage has been performed as reported elsewhere [15]. Four $60 \mathrm{~mL}$ aliquots of saline solution 
Table 1 Demographic, clinical and lung involvement characteristics of 46 scleroderma patients

\begin{tabular}{|c|c|c|c|}
\hline & All scleroderma Patients & 24 scleroderma pts with alveolitis & 22 scleroderma pts without alveolitis \\
\hline Age $(y$, mean $\pm S D)$ & $55.1 \pm 14$ & $60.6 \pm 11.7^{*}$ & $49 \pm 14$ \\
\hline Disease duration $(y \text {, mean } \pm S D)^{* *}$ & $6.1 \pm 6.2$ & $5.4 \pm 5.4$ & $6.9 \pm 7.1$ \\
\hline Early disease (<3 y) n (\%) & $21(45.6 \%)$ & $12(50 \%)$ & $9(40.9 \%)$ \\
\hline Female n (\%) & $36(78.3 \%)$ & $20(83.3 \%)$ & $16(72.7 \%)$ \\
\hline dSSC n (\%) & $15(32.6 \%)$ & 7 (29.2\%) & $8(36.4 \%)$ \\
\hline AntiScl70 n (\%) & $28(60.9 \%)$ & $16(66.7 \%)$ & $12(54.5 \%)$ \\
\hline Anticentromere n (\%) & $5(10.9 \%)$ & $2(8.3 \%)$ & $3(12.6 \%)$ \\
\hline Antiribonucleoprotein n (\%) & $3(6.5 \%)$ & $1(4.2 \%)$ & $2(9.1 \%)$ \\
\hline Antinucleolus n (\%) & $3(6.5 \%)$ & $2(8.3 \%)$ & $1(4.5 \%)$ \\
\hline FVC\% (mean \pm SD) & $93.1 \pm 20.9$ & $89.2 \pm 23.1$ & $97.3 \pm 17.8$ \\
\hline DLCO\% (mean \pm SD) & $52.3 \pm 14.8$ & $48.9 \pm 17.1$ & $56 \pm 11.2$ \\
\hline Restrictive lung disease n (\%) & $14(30.4 \%)$ & $11(45.8 \%)^{*}$ & $3(13.6 \%)$ \\
\hline Ground glass score (mean \pm SD) & $7.8 \pm 5.6$ & $9.7 \pm 5.8^{*}$ & $5.6 \pm 4.6$ \\
\hline Interstitial score (mean \pm SD) & $6.3 \pm 2.7$ & $6.6 \pm 2.8$ & $5.9 \pm 2.6$ \\
\hline Alveolitis on BALF & $24(52.2 \%)$ & / & / \\
\hline PASP (mmHg; mean \pm SD) & $27.8 \pm 5.7$ & $30.8 \pm 5.7^{*}$ & $25.1 \pm 4.2$ \\
\hline HPAP n (\%) & $5(10.9 \%)$ & $5(20.8 \%)^{*}$ & 0 \\
\hline Treatment n (\%) & $12(26.1 \%)$ & $12(50.0 \%)$ & 0 \\
\hline Smokers n (\%) & $6(13 \%)$ & $4(16.7 \%)$ & $2(9.1 \%)$ \\
\hline
\end{tabular}

pts: patients; y: years; SD: standard deviation; n: number; dSSc: diffuse disease; FVC: forced vital capacity; DLCO: carbon monoxide diffusing capacity; BALF: bronchoalveolar lavage fluid; PASP: pulmonary arterial systolic pressure; HPAP: high pulmonary arterial pressure;

*p < 0.05: pts with alveolitis versus pts without alveolitis.

** first SSc sign other than Raynaud's phenomenon.

have been instilled and BALF mean recovery has been $112.4 \pm 30.3 \mathrm{~mL}$ in the patients with alveolitis, $129.6 \pm$ $25.7 \mathrm{~mL}$ in the patients without alveolitis, and 100.4 \pm $28.4 \mathrm{~mL}$ in control subjects. The percentages of alveolar macrophages, lymphocytes, neutrophils and eosinophils have been recorded. Cells with the forward and side scatter properties of lymphocytes have been analyzed on a flow cytometer (Beckman Coulter, EXPO32). Used antibodies included Phycoerythrincyanin(PC5)-conjugated anti-CD3 monoclonal antibodies (mAb), Phycoerythrin Texas red(ECD)-conjugated anti-CD4 mAb, fluorescein isothiocyanate(FITC)-conjugated anti-CD8 $\mathrm{mAb}$, Phycoerythrin(PE)-conjugated anti-CD19 mAb, (all from Beckman Coulter, Marseille, France). Alveolitis has been diagnosed when the percentage of neutrophils was ${ }^{3} 3 \%$ and/or eosinophils ${ }^{3} 2 \%$ [21].

Among the patients with alveolitis, 5 received azathioprine $100 \mathrm{mg} /$ die per os for 12 months, and 7 received cyclophosphamide $100 \mathrm{mg} /$ die per os for 8.6 weeks $(6 \mathrm{~g})$ then followed by azathioprine as above, 12 received only conventional therapies [15].

\section{BALF collection and preparation for RP-HPLC-ESI-MS analysis}

Immediately after collection an acidic solution of $0.2 \%$ aqueous trifluoroacetic acid has been added in ice bath to $5 \mathrm{~mL}$ BALF in 1:1 v:v ratio, and the solution has been centrifuged at 10,000 g for $10 \mathrm{~min}$. The supernatant has been separated from the precipitate. The acid clear specimen has been freeze-dried, dissolved in $1 \mathrm{~mL}$ of $0,2 \%$ aqueous trifluoroacetic acid solution and $100 \mathrm{ul}$ aliquots of the solution directly injected into the RP-HPLC-MS apparatus. The remaining acidic solution has been stored to $-80^{\circ} \mathrm{C}$ for further analysis.

\section{RP-HPLC-ESI-MS analysis}

All HPLC-MS reagents have been of analytical grade and have been purchased from Farmitalia Carlo Erba (Milan, Italy), Merck (Damstadt, Germany), and Sigma-Aldrich (St. Louis, MI, USA). Standards of $\beta$-thymosins have been purchased from Bachem (Bubendorf, Switzerland).

The HPLC-ESI-IT-MS apparatus has been a Surveyor HPLC system (Thermo Fisher, San Jose, CA, USA) connected by a $\mathrm{T}$ splitter to a photo diode-array detector and to an LCQ Deca-XP Plus mass spectrometer. The chromatographic column has been a $150 \times 2.1 \mathrm{~mm}$ Vydac (Hesperia, CA, USA) C8 column, with $5 \mu \mathrm{m}$ particle diameter. The eluents have been (A) $0.056 \%$ aqueous TFA and (B) $0.050 \%$ TFA in ACN/water $80: 20 \mathrm{v} / \mathrm{v}$. The applied gradient has been linear from 0 to $55 \%$ of (B) in $40 \mathrm{~min}$, at a flow rate of $0.30 \mathrm{~mL} / \mathrm{min}$. The $\mathrm{T}$ splitter has addressed $0.20 \mathrm{~mL} / \mathrm{min}$ toward the diode-array detector and $0.10 \mathrm{~mL} / \mathrm{min}$ toward the ESI source. The diode array detector has been set at 214 and $276 \mathrm{~nm}$. Mass spectra 
have been collected every $3 \mathrm{~ms}$ in positive ion mode. MS spray voltage has been $4.50 \mathrm{kV}$ and the capillary temperature $220^{\circ} \mathrm{C}$.

Some samples of BALF have been also analyzed by an Ultimate 3000 Nano/Micro-HPLC apparatus (Dionex, Sunnyvale, CA, USA) equipped with an FLM-3000-Flow manager module coupled to an LTQ Orbitrap XL apparatus (Thermo Fisher). The column has been a Biobasic 8 capillary column with $3 \mathrm{~lm}$ particle diameter (column dimension $180 \mathrm{~lm}$ id610 cm). The chromatographic eluents have been (A) $0.1 \%$ aqueous formic acid and (B) $0.1 \%$ formic acid in ACN. The applied gradient has been 0-4 min 5\% B, 4-38 min from 5 to $50 \%$ B (linear), 38-41 min from 50 to $90 \%$ B (linear), at a flow rate of $4 \mu \mathrm{L} / \mathrm{min}$. Mass spectra have been collected in full scan (MS data) and also in data-dependent scan (MS/MS data) mode with a capillary temperature of $250^{\circ} \mathrm{C}$, a sheath gas flow of 17 arbitrary unities, a source voltage of $3.6 \mathrm{kV}$, and a capillary voltage of $32 \mathrm{~V}$. Measurements have been performed in the positive ion mode and mass accuracy has been calibrated before measurements. Selected protein charge states have been isolated with a width of $\mathrm{m} / \mathrm{z}$ 6-10 and activated for $30 \mathrm{~ms}$ using $30 \%$ normalized collision energy and an activation q of 0.25 .

\section{Identification and quantification of B-thymosins}

$\beta$-thymosins have been identified in the HPLC-ESI pattern by comparison with peptide standards. Sequences of thymosin $\beta_{4}$ and thymosin $\beta_{10}$ have been also confirmed by high resolution dynamic MS/MS experiments performed by the LTQ Orbitrap XL apparatus on a BALF sample using the conditions described in the previous section and obtaining fragmentations comparable to that previously reported for the identification of thy$\operatorname{mosin} \beta_{4}$ and thymosin $\beta_{10}$ in human saliva [5].

Satisfactory linear correlation has been found between the absolute quantity of thymosin $\beta_{4}$ and thymosin $\beta_{10}$ peptide standards and the extracted ion current peak area $\left(R=0.999\right.$; coefficient $2.16 \times 10^{6}$ extracted ion current peak area per picomole of peptide). Thus, the extracted ion current peak area has been used to calculate concentrations, taking into account the correlation coefficient and the injected sample volume. The latter has corresponded to $100 \mu \mathrm{l}$ in experiments performed on 10 times concentrated BALF. The extracted ion current peaks have been revealed by selecting the following ions: thymosin $\beta 4,[\mathrm{M}+5 \mathrm{H}] 5+=993.8 \mathrm{~m} / \mathrm{z},[\mathrm{M}+4 \mathrm{H}] 4+=$ $1241.9 \mathrm{~m} / \mathrm{z},[\mathrm{M}+3 \mathrm{H}] 3+=1655.5 \mathrm{~m} / \mathrm{z}$; thymosin $\beta 4$ sulfoxide $[\mathrm{M}+5 \mathrm{H}] 5+=996.9 \mathrm{~m} / \mathrm{z},[\mathrm{M}+4 \mathrm{H}] 4+=1245.9 \mathrm{~m} / \mathrm{z}$, $[\mathrm{M}+3 \mathrm{H}] 3+=1660.8 \mathrm{~m} / \mathrm{z}$; thymosin $\beta 10,[\mathrm{M}+5 \mathrm{H}] 5+=$ $988.3 \mathrm{~m} / \mathrm{z},[\mathrm{M}+4 \mathrm{H}] 4+=1235.1 \mathrm{~m} / \mathrm{z},[\mathrm{M}+3 \mathrm{H}] 3+=1646.5$ $\mathrm{m} / \mathrm{z}$. Windows for all these values have been $\pm 0.5 \mathrm{~m} / \mathrm{z}$. The percentage error of the measurements has been less than $10 \%$.

\section{Data analysis}

Deconvolution of averaged ESI mass spectra has been automatically performed either by the software provided with the Deca-XP instrument (Bioworks Browser) or by MagTran 1.0 software (Zhang and Marshall, 1998). Experimental mass values have been compared with average theoretical values available at the Swiss-Prot data bank (http://us.expasy.org/tools), where thymosin $\beta_{4}$ and thymosin $\beta_{10}$ have the codes P62328 and P63313, respectively. Deconvolutions of Orbitrap MS/MS data have been performed using the software provided with the LTQ Orbitrap XL (Xctract on QualBrowser 2.0).

\section{Statistical analysis}

Data have been analyzed using SPSS 12.0 (SPSS. Chicago. IL-USA). Categorical variables have been analyzed using $\mathrm{c}^{2}$ test or Fisher's test, depending on sample size restrictions and the Odds' Ratio (OR) with 95\% confidence interval (CI95\%) have been calculated. Mann-Whitney's or Wilcoxon's rank sum test, as appropriate, have been used to compare continuous variable. Spearman's rank correlation have been used to evaluate the relationship between different disease parameters. A value of $\mathrm{p}<0.05$ has been considered statistically significant.

\section{Results}

\section{$\beta$-thymosins in the BALF of scleroderma patients and controls}

Considering the total $\beta$-thymosin content, the percentages of thymosin $\beta_{4}, \beta_{4}$ sulfoxide and $\beta_{10}$ have been similar in patients and controls $(82.4 \%, 4.3 \%, 13.3 \%$ versus $82.4 \%, 5.0 \%, 12.6 \%$, respectively).

Thymosin $\beta_{4}$ has been consistently detected in all the BALF of both patients and controls. Thymosin $\beta_{4}$ sulfoxide was detected in $14(30 \%)$ of the scleroderma patients and in 5 (33.3\%) of the controls and thymosin $\beta_{10}$ in $28(60.9 \%)$ of the scleroderma patients and in 8 (53.3\%) of the controls $(\mathrm{p}=\mathrm{ns})$ (Table 2).

Thymosin $\beta_{4}$ concentration has been significantly higher in the BALF of the scleroderma patients than in the controls $(0.310 \pm 0.372 \mu \mathrm{mol} / \mathrm{L}$ versus $0.112 \pm 0.084$ $\mu \mathrm{mol} / \mathrm{L}$, respectively; $\mathrm{p}=0.008)($ Table 2 and figure 1 ). Thymosin $\beta_{4}$ sulfoxide and thymosin $\beta_{10}$ levels have been also found to be higher in the BALF of the scleroderma patients compared to the controls, yet the differences have been not significant (Table 2 and figure 1).

Among the control subjects, higher thymosin $\beta_{4}$ and $\beta_{4}$ sulfoxide levels have been found in the BALF of the smokers $(0.238 \pm 0.037$ and $0.023 \pm 0.011 \mu \mathrm{mol} / \mathrm{L}$ versus $0.08 \pm 0.058$ and $0.003 \pm 0.007 \mu \mathrm{mol} / \mathrm{L} ; \mathrm{p}=0.014$ and $\mathrm{p}=0.006$, respectively). Thymosin $\beta_{4}$ sulfoxide has been detected in the BALF of $3 / 3$ smoking control subjects and in $2 / 6$ scleroderma smoking patients. 
Table 2 Concentration and frequency of $\beta$-thymosins in scleroderma patients and controls

\begin{tabular}{|c|c|c|}
\hline & 46 scleroderma pts & 15 controls \\
\hline presence of $\mathrm{T} \beta_{4}, \mathrm{n}$ pts (\%) & $46(100 \%)$ & $15(100 \%)$ \\
\hline$T \beta_{4}(\mu \mathrm{mol} / \mathrm{L}$, mean $\pm \mathrm{SD})$ & $0.310 \pm 0.372^{*}$ & $0.112 \pm 0.084$ \\
\hline (median, range) & $(0.21,0-2.1)$ & $(0.09,0-0.26)$ \\
\hline presence of sT $\beta_{4}, \mathrm{n}$ pts (\%) & $14(30 \%)$ & $5(33 \%)$ \\
\hline$s T \beta_{4}(\mu \mathrm{mol} / \mathrm{L}$, mean $\pm \mathrm{SD})$ & $0.016 \pm 0.041$ & $0.007 \pm 0.011$ \\
\hline (median, range) & $(0,0-0.24)$ & $(0.01,0-0.08)$ \\
\hline presence of $\mathrm{T} \beta_{10}, \mathrm{n}$ pts (\%) & $28(60.9 \%)$ & 8 (53.3\%) \\
\hline $\mathrm{T} \beta_{10}(\mu \mathrm{mol} / \mathrm{L}$, mean $\pm \mathrm{SD})$ & $0.050 \pm 0.072$ & $0.017 \pm 0.022$ \\
\hline (median, range) & $(0.02,0-0.3)$ & $(0,0-0.04)$ \\
\hline $\mathrm{T} \beta_{4} / \mathrm{ST} \beta_{4}$ ratio $($ mean $\pm \mathrm{SD})$ & $9.4 \pm 2.6$ & $11.0 \pm 4.6$ \\
\hline
\end{tabular}

$T \beta_{4}$ : thymosin $\beta_{4} ; \mathrm{n}$ : number; pts: patients; SD: standard deviation; $\mathrm{sT} \beta_{4}$ : thymosin $\beta_{4}$ sulfoxide; $T \beta_{10}$ : thymosin $\beta_{10}$.

${ }^{*} \mathrm{p}<0.05$ : pts versus controls.

$\beta$-thymosins in the BALF of scleroderma patients with alveolitis and without alveolitis

Among the scleroderma patients, thymosin $\beta_{4}$ sulfoxide has been detected in 10 (41.6\%) of the patients with alveolitis versus $4(18.1 \%)$ of the patients without alveolitis $(\mathrm{p}=\mathrm{ns})$ (Table 3$)$. Thymosin $\beta_{10}$ has been detected in $13(54.2 \%)$ of the patients with alveolitis versus 15 (68.2\%) of the patients without alveolitis ( $\mathrm{p}=\mathrm{ns}$ ) (Table 3 ).

In addition, thymosin $\beta_{4}$ sulfoxide levels has been significantly higher and thymosin $\beta_{4} / \beta_{4}$ sulfoxide ratio has been significantly lower in the scleroderma patients with alveolitis compared to the patients without alveolitis $(0.025 \pm 0.052$ and $7.3 \pm 4.6 \mu \mathrm{mol} / \mathrm{L}$ versus $0.006 \pm 0.02$ and $14.6 \pm 4.9 \mu \mathrm{mol} / \mathrm{L} ; \mathrm{p}=0.052$ and $\mathrm{p}=0.024$, respectively) (Table 3 and figure 1). Although thymosin $\beta_{4}$ and thymosin $\beta_{10}$ levels have been higher in the BALF of scleroderma patients with alveolitis compared to the patients without alveolitis, the differences have been not significant (Table 3 and figure 1 ). No correlations have been found between thymosin $\beta_{10} / \beta_{4}$ ratio and any lung involvement indices.

\section{Correlation between BALF $\beta$-thymosin levels and BALF cytology}

A significant, even if weak, correlation has been found between thymosin $\beta_{4}$ sulfoxide levels and BALF neutrophil percentage count $(p=0.010 ; r=+0.36$ ) (Figure 2$)$. Moreover, thymosin $\beta_{4}$ sulfoxide levels have inversely correlated with BALF CD4/CD8 ratio ( $\mathrm{p}=0.007 ; \mathrm{r}=-0.40$ ) (Figure 2) and CD4 percentage count $(\mathrm{p}=0.036 ; \mathrm{r}=-0.32)$ and directly with CD8 percentage count $(\mathrm{p}=0.016 ; \mathrm{r}=+0.36)$.

Thymosin $\beta_{10}$ levels have directly correlated with BALF CD3 ( $\mathrm{p}=0.035 ; \mathrm{r}=+0.31)$ and CD4 percentage count $(\mathrm{p}=0.039 ; \mathrm{r}=+0.31)$ (Figure 2$)$.

\section{Correlation between BALF $\beta$-thymosin levels and lung involvement parameters}

The scleroderma patients with restrictive lung disease have had higher thymosin $\beta_{4}$ sulfoxide levels (0.034 \pm $0.065 \mu \mathrm{mol} / \mathrm{L}$ versus $0.008 \pm 0.022 \mu \mathrm{mol} / \mathrm{L} ; \mathrm{p}=0.042$ ) This data has associated with the significantly higher frequency of restrictive lung disease in the patients with alveolitis. Thymosin $\beta_{10}$ levels have inversely with DLCO ( $\mathrm{p}=0.009 ; \mathrm{r}=-0.38$ ) (Figure 2).

The scleroderma patients experiencing a significant alveolar score worsening on high resolution computed tomography after one-year follow-up have had lower
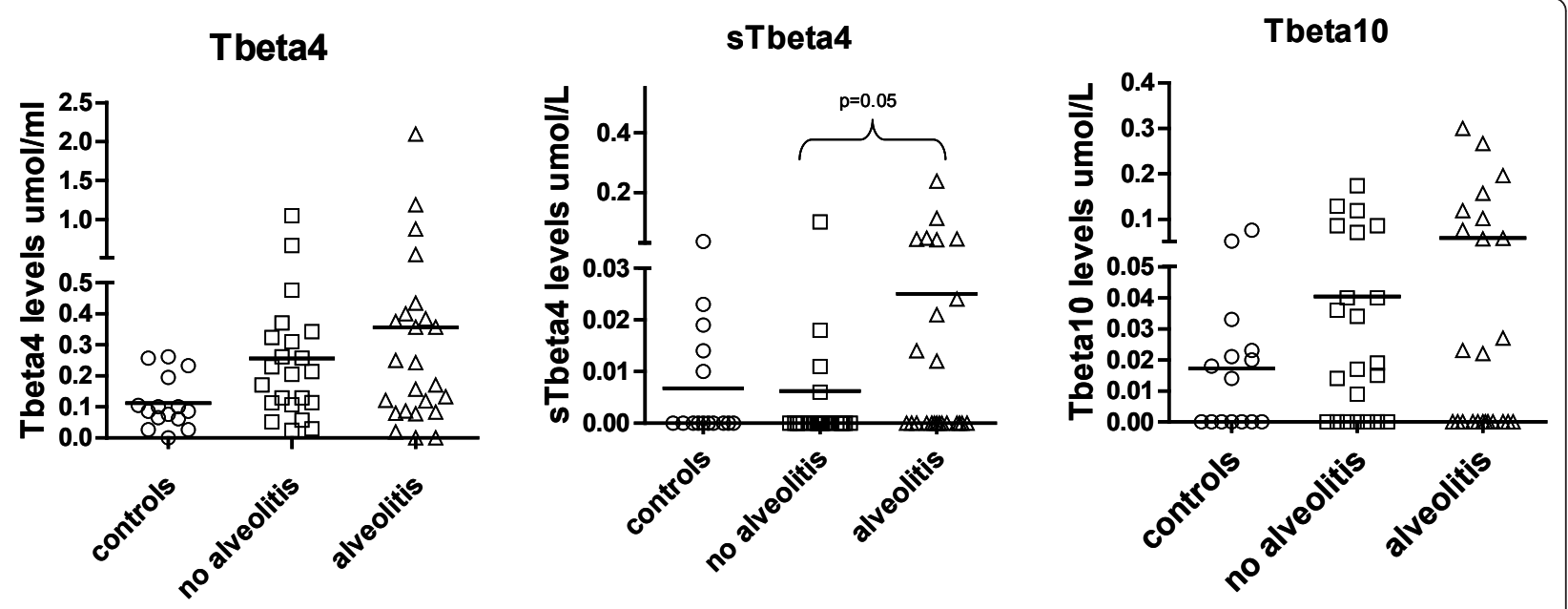

BALF: bronchoalveolar lavage fluids; T: thymosin; s: sulfoxide

Figure 1 BALF $\beta$-thymosins concentrations in scleroderma patients with and without alveolitis and in controls 
Table 3 Concentration and frequency of $\beta$-thymosins in scleroderma patients with or without alveolitis

\begin{tabular}{|c|c|c|}
\hline & $\begin{array}{l}24 \text { scleroderma pts } \\
\text { with alveolitis }\end{array}$ & $\begin{array}{l}22 \text { scleroderma pts } \\
\text { without alveolitis }\end{array}$ \\
\hline $\begin{array}{l}\text { presence of } T \beta_{4,} \\
n \text { pts (\%) }\end{array}$ & $24(100 \%)$ & $22(100 \%)$ \\
\hline $\begin{array}{l}T \beta_{4}\left(\mu \mathrm{mol} / \mathrm{L}_{1}\right. \\
\text { mean } \pm \mathrm{SD})\end{array}$ & $0.356 \pm 0.464$ & $0.256 \pm 0.236$ \\
\hline (median, range) & $(0.21,0-2.1)$ & $(0.13,0-1.0)$ \\
\hline $\begin{array}{l}\text { presence of sT } \beta_{4} \\
n \text { pts (\%) }\end{array}$ & $10(41.6 \%)$ & $4(18.1 \%)$ \\
\hline $\begin{array}{l}\mathrm{sT} \beta_{4}(\mu \mathrm{mol} / \mathrm{L}, \\
\text { mean } \pm \mathrm{SD})\end{array}$ & $0.025 \pm 0.052^{*}$ & $0.006 \pm 0.219$ \\
\hline (median, range) & $(0,0-0.24)$ & $(0,0-0.1)$ \\
\hline $\begin{array}{l}\text { presence of } \mathrm{T} \beta_{10} \\
\mathrm{n} \text { pts }(\%)\end{array}$ & $13(54.2 \%)$ & $15(68.2 \%)$ \\
\hline $\begin{array}{l}T \beta_{10}(\mu \mathrm{mol} / \mathrm{L}, \\
\text { mean } \pm \mathrm{SD})\end{array}$ & $0.059 \pm 0.088$ & $0.040 \pm 0.049$ \\
\hline (median, range) & $(0.01,0-0.3)$ & $(0.02,0-0.17)$ \\
\hline $\begin{array}{l}\mathrm{T} \beta_{4} / \mathrm{sT} \beta_{4} \text { ratio } \\
\text { (mean } \pm \mathrm{SD})\end{array}$ & $7.328 \pm 4.626 *$ & $14.582 \pm 4.907$ \\
\hline
\end{tabular}

$T \beta_{4}$ : thymosin $\beta_{4} ;$ n: number; pts: patients; SD: standard deviation; $\mathrm{ST} \beta_{4}$ : thymosin $\beta_{4}$ sulfoxide; $T \beta_{10}$ : thymosin $\beta_{10}$.

${ }^{*} p<0.05$ : pts versus controls.

BALF thymosin $\beta_{4}$ levels $(0.214 \pm 0.290$ versus $0.386 \pm$ $0.457 \mu \mathrm{mol} / \mathrm{L}$, respectively; $\mathrm{p}=0.034)$. There have been no correlations between $\beta$-thymosin levels and pulmonary function test decline. There were no differences between treated and untreated patients.

\section{Discussion}

In this study we have described for the first time the presence of $\beta$-thymosins in human BALF. The BALF relative proportions of thymosin $\beta_{4}$ (about $85 \%$ ), $\beta_{4}$ sulfoxide (about $5 \%$ ) and $\beta_{10}$ (about 10\%) have been similar to those reported in other biological fluids and in the intracellular compartment $[2,5]$. However, thymosin $\beta_{4}$ concentration in BALF $(0.1 \mu \mathrm{M})$ was about 10 -fold higher than that reported in the plasma $(10 \mathrm{nM})[22,23]$. Although the mechanism of thymosin $\beta_{4}$ extra-cellular release is not known, it seems that thymosin $\beta_{4}$ might escape from damaged cells because of its small size [23]. Then, considering that pulmonary epithelial cells and alveolar macrophages are constantly exposed to environmental toxicants, it can be hypothesized a passive cellular release of thymosin $\beta_{4}$ rather than an active compartmentalization of thymosin $\beta_{4}$ in the lung where it would exert a cyto-protective effect. In this context it could be explained the higher BALF thymosin $\beta_{4}$ levels founded in smokers and in a pathological condition such as scleroderma interstitial lung disease. Interestingly, the scleroderma patients experiencing a worsening in the alveolar score had relatively lower BALF thymosin $\beta_{4}$ levels. This data could support the role of thymosin $\beta_{4}$ in tissue repairing as already reported in other conditions as wound healing [6], ischemic heart disease [24], and cornea lesions [25]. These data are consistent with the ability of thymosin $\beta_{4}$ to down-regulate a number of key inflammatory cytokines like tumor necrosis factor- $\alpha$ [9].

Our study suggests but does not clarify the possible involvement of $\beta$-thymosins in scleroderma lung disease; however, considering the significant difference (about 3 folds) in thymosin $\beta_{4}$ levels in the BALF of scleroderma patients compared to normal counterpart, thymosin $\beta_{4}$ could be considered a biomarker of lung involvement in systemic sclerosis. This seems to be particularly interesting in the light of a recent peptidomic study reporting that plasma thymosin $\beta_{4}$ is a biomarker of rheumatoid arthritis, another rheumatologic disease with lung involvement [26]. In parallel, thymosin $\beta_{4}$ sulfoxide could be considered a biomarker of lung oxidative stress. In fact, the higher levels of thymosin $\beta_{4}$ sulfoxide found in smoking control subjects could mirror the oxidative stress status. Methionine residues are somewhat sensitive to oxidation, and many proteins can be inactivated through this mechanism. In smokers, methionine oxidation is essential for $\alpha(1)$-antitrypsin inactivation and pathologic lung remodeling [27]. Indeed, thymosin $\beta_{4}$ oxidation could actually represent a scavenger mechanism, able to reduce the negative effects of oxidative stress on other lung proteins and enzymes. It has been reported that scleroderma patients with alveolitis had a more extensive interstitial lung disease, a higher risk to worsen and a poor prognosis [28]. All pulmonary diseases with an inflammatory component, like alveolitis, have also a component of oxidative stress. This explains the higher thymosin $\beta_{4}$ sulfoxide levels in the subgroup of scleroderma patients with alveolitis and the positive correlation between thymosin $\beta_{4}$ sulfoxide and both BALF neutrophil percentage count and CD8 cells. BALF CD8 cells are, in fact, associated with the production of T-helper 2 cytokines and the decline of pulmonary function in scleroderma patients [29].

Although many studies on thymosin $\beta_{10}$ have been reported, its functions and molecular mechanisms in human diseases are largely unknown. Even if thymosin $\beta_{4}$ and $\beta_{10}$ have identical actin-binding sites, they have different extracellular activity and different expression pattern during embryological development or in cancer. Our data show that thymosin $\beta_{4}$ and $\beta_{10}$ have a similar expression pattern in scleroderma interstitial lung disease, maybe due to a passive release from damaged cells. The relationship between thymosin $\beta_{10}$ and BALF lymphocyte percentage count indicates that thymosin $\beta_{10}$ could be released by infiltrated and activated BALF lymphocytes [3]. The negative correlation between thymosin $\beta_{10}$ and DLCO suggests a potential inhibiting role of thymosin $\beta_{10}$ on alveolar-capillary permeability. Recently a positive correlation between BALF VEGF and DLCO 

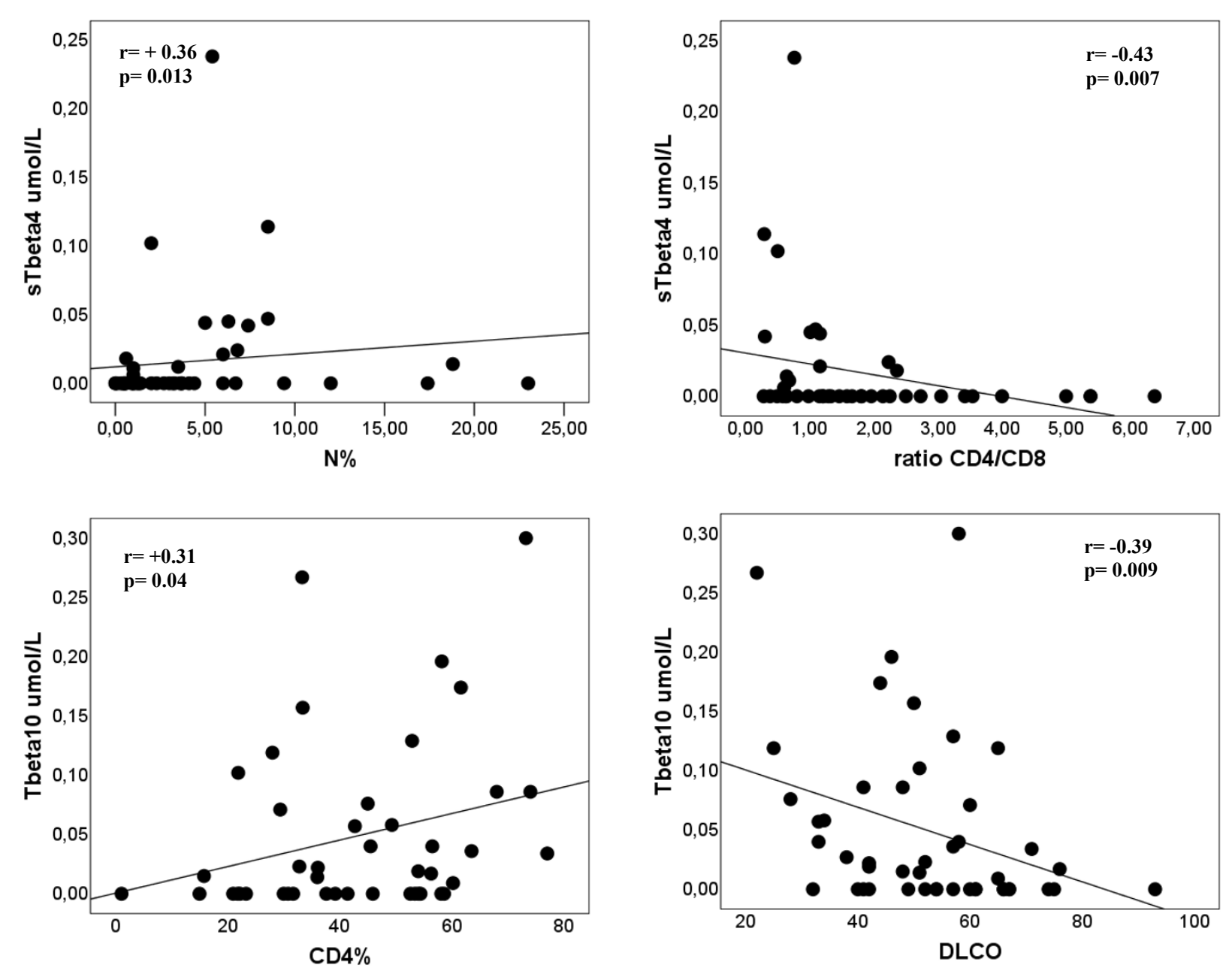

T: thymosin; s: sulfoxide; N\%: BALF neutrophil percentage count; CD4/CD8: ratio between BALF

CD4 cells and BALF CD8 cells; CD4\%: BALF CD4 percentage count; DLCO: carbon monoxide diffusing capacity; BALF: bronchoalveolar lavage fluid.

Figure 2 Positive correlation between thymosin $\beta_{4}$ sulfoxide and BALF neutrophil percentage count and between thymosin $\beta_{10}$ and BALF CD4 percentage count. Negative correlation between thymosin $\beta_{4}$ sulfoxide and BALF CD4/CD8 ratio and between thymosin $\beta_{10}$ and DLCO.

[30] has been reported, thus considering the antiangiogenetic effect of thymosin $\beta_{10}$ and the main role of VEGF in the regulation of lung permeability, it will be interesting to investigate the possible relationship between thymosin $\beta_{10}$ and VEGF in the lung.

\section{Conclusions}

In this study we have described for the first time the presence of $\beta$-thymosins in human BALF with a concentration about 10-fold higher than that reported in the plasma. Moreover, we found higher concentrations of thymosin $\beta 4$ in the BALF of scleroderma patients with lung involvement compared to the normal counterpart and of thymosin $\beta 4$ sulfoxide in the subset of scleroderma patients with alveolitis, thus suggesting a possible role of these paracrine factors in systemic sclerosis as biomarkers of interstitial lung disease and alveolitis, respectively. Interestingly, the scleroderma patients experiencing a worsening in the alveolar score at one-year follow-up were found to have lower thymosin $\beta 4$ levels. We have hypothesized that the release of high amounts of thymo$\sin \beta 4$ in the extracellular compartment during lung 
fibrogenesis is due to epithelial damage and that thymo$\sin \beta 4$ may exert a cyto-protective effect during lung injury being BALF lower levels associated to interstitial lung disease progression. Further studies in a larger number of SSc patients are needed to validate BALF $\beta$-thymosins as biomarkers of lung involvement. Moreover, it would be clinically helpful to investigate if $\beta$-thymosin plasma levels correlate to BALF levels

\author{
Author details \\ 'Department of Rheumatology, Catholic University, Rome, Italy. ${ }^{2}$ Institute of \\ Biochemistry and Clinical Biochemistry, Catholic University, Rome, Italy. \\ ${ }^{3}$ Department of Sciences Applied to Biosystems, Cagliari University, Cagliari, \\ Italy. ${ }^{4}$ Department of Pneumology, Catholic University, Rome, Italy. ${ }^{5}$ Institute \\ for the Chemistry of Molecular Recognition, CNR, Catholic University, Rome, \\ Italy.
}

\section{Authors' contributions}

MDS conceived the study, coordinated the groups, gave substantial contribution to acquisition of data, performed statistical analysis and wrote the study; RI and SLB gave substantial contribution to acquisition of data, analysis and interpretation of data; GP, CF, Fl, GZ, MB, and TC, participated in the design of the study and to the statistical analysis and gave substantial contribution to acquisition of the data; LF, FV, and GP gave substantial contribution to acquisition of the data; IM, CM, and GF participated in the design of the study and helped to draft the manuscript. All authors read and approved the final manuscript.

\section{Competing interests}

The authors declare that they have no competing interests.

Received: 20 November 2010 Accepted: 11 February 2011 Published: 11 February 2011

\section{References}

1. Hannappel E: b-Thymosins. Ann N Y Acad Sci 2007, 1112:21-37.

2. Huff T, Muller CS, Otto AM, Natzker R, Hannappel E: beta-Thymosins, small acidic peptides with multiple functions. Int I Biochem Cell Biol 2001, 33:205-220.

3. Santelli G, Califano D, Chiappetta G, Vento MT, Bartoli PC, Zullo F, Trapasso F, Viglietto G, Fusco A: Thymosin beta-10 gene overexpression is a general event in human carcinogenesis. Am J Pathol 1999, 155:799-804.

4. Capelli E, Campo I, Panelli S, Damiani G, Barbone MG, Lucchelli A, Cuccia M: Evaluation of gene expression in human lymphocytes activated in the presence of melatonin. Int Immunopharmacol 2002, 2(7):885-92.

5. Inzitari R, Cabras T, Pisano E, Fanali C, Manconi B, Scarano E, Fiorita A, Paludetti G, Manni A, Nemolato S, Faa G, Castagnola M, Messana I: HPLCESI-MS analysis of oral human fluids reveals that gingival crevicular fluid is the main source of oral thymosins beta(4) and beta(10). J Sep Sci 2009, 32(1):57-63

6. Malinda KM, Sidhu GS, Mani H, Banaudha K, Maheshwari RK, Goldstein AL, Kleinman HK: Thymosin beta4 accelerates wound healing. J Invest Dermatol 1999, 113(3):364-8.

7. Smart N, Rossdeutsch A, Riley PR: Thymosin b4 and angiogenesis: modes of action and therapeutic potential. Angiogenesis 2007, 10:229-241.

8. Zhang T, Li X, Yu W, Yan Z, Zou H, He X: Overexpression of thymosin beta-10 inhibits VEGF mRNA expression, autocrine VEGF protein production, and tube formation in hypoxia-induced monkey choroidretinal endothelial cells. Ophthalmic Res 2009, 41(1):36-43.

9. Barnaeva E, Nadezhda A, Hannappel E, Sjogren MH, Rojkind M: Thymosin beta4 upregulates the expression of hepatocyte growth factor and downregulates the expression of PDGF-beta receptor in human hepatic stellate cells. Ann NY Acad Sci 2007, 1112:154-60.

10. Sosne G, Qiu P, Christopherson PL, Wheater MK: Thymosin $b_{4}$ suppression of corneal NFkB: a potential anti-infllammatory pathway. Exp Eye Res 2007, 84:663-669.
11. Young JD, Lawrence AJ, MacLean AG, Leung BP, McInnes IB, Canas B, Pappin DJ, Stevenson RD: Thymosin beta 4 sulfoxide is an antiinflammatory agent generated by monocytes in the presence of glucocorticoids. Nat Med 1999, 5(12):1424-7.

12. Badamchian M, Damavandy AA, Damavandy H, Wadhwa SD, Katz B, Goldstein AL: Identification and quantification of thymosin $\beta 4$ in human saliva and tears. Ann NY Acad Sci 2007, 1112:458-465.

13. Subcommittee for scleroderma criteria of the American Rheumatism Association diagnostic and therapeutic criteria committee: Preliminary criteria for the classification of systemic sclerosis (scleroderma). Arthritis Rheum 1980, 23:581-90.

14. LeRoy EC, Black C, Fleishmajer R, Jablonska S, Krieg T, Medsger TA, Rowell N, Wolheim F: Scleroderma (systemic sclerosis): classification, subset and pathogenesis. J Rheumatol 1988, 15:202-5.

15. De Santis M, Bosello S, La Torre G, Capuano A, Tolusso B, Pagliari G, Pistelli R, Danza FM, Zoli A, Ferraccioli G: Functional, radiological and biological markers of alveolitis and infections of the lower respiratory tract in patients with systemic sclerosis. Respir Res 2005, 17:6, 96.

16. American Thoracic Society: Standardization of Spirometry-1994 Update. Am J Respir Crit Care Med 1995, 152:1107-1136.

17. American Thoracic Society: Single breath Carbon Monoxide Diffusing Capacity (Transfer Factor). Recommendation for a standard technique1995 Update. Am J Respir Crit Care Med 1995, 152:2185-2198.

18. Egan JJ, Martinez FJ, Wells AU, Williams T: Lung function estimates in idiopathic pulmonary fibrosis: the potential for a simple classification. Thorax 2005, 60:270-273.

19. Behr J, Furst DE: Pulmonary function tests. Rheumatol 2008, 47:65-67.

20. Medsger TA, Bombardieri S, Czirjak L, Scorza R, Della Rossa A, Bencivelli W: Assessment of disease severity and prognosis in Scleroderma. Clin Exp Rheumatol 2003, 29:42-46.

21. Tashkin DP, Elashoff R, Clements PJ, Goldin J, Roth MD, Furst DE, Arriola E, Silver R, Strange C, Bolster M, Seibold JR, Riley DJ, Hsu VM, Varga J, Schraufnagel DE, Theodore A, Simms R, Wise R, Wigley F, White B, Steen V, Read C, Mayes M, Parsley E, Mubarak K, Connolly MK, Golden J, Olman M, Fessler B, Rothfield N, Metersky M, Scleroderma Lung Study Research Group: Cyclophosphamide versus placebo in scleroderma lung disease. N Engl J Med 2006, 354(25):2655-66.

22. Hannappel $\mathrm{E}$, van Kampen M: Determination of thymosin beta 4 in human blood cells and serum. J Chromatogr 1987, 26:397, 279-285.

23. Mannherz HG, Hannappel E: The $\beta$-Thymosins: intracellular and extracellular activities of a versatile actin binding protein family. Cell Motil Cytoskeleton 2009, 66:839-851.

24. Bock-Marquette I, Saxena A, White MD, Dimaio JM, Srivastava D: Thymosin beta4 activates integrin-linked kinase and promotes cardiac cell migration, survival and cardiac repair. Nature 2004, 432:466-72.

25. Sosne G, Christopherson PL, Barrett RP, Fridman R: Thymosin $b_{4}$ modulates corneal matrix metalloproteinase levels and polymorphonuclear cell infiltration after alkali injury. Invest Ophthalmol Vis Sci 2005, 46:2388-2395.

26. Zheng $X$, Wu S, Hincapie M, Hancock WS: Study of the human plasma proteome of rheumatoid arthritis. J Chromatogr A 2009, 1216:3538-3545.

27. Taggart C, Cervantes-Laurean D, Kim G, McElvaney NG, Wehr N, Moss J, Levine RL: Oxidation of either methionine 351 or methionine 358 in alpha 1-antitrypsin causes loss of anti-neutrophil elastase activity. J Biol Chem 2000, 275(35):27258-27265.

28. Kowal-Bielecka O, Kowal K, Highland KB, Silver RM: Bronchoalveolar Lavage Fluid in Scleroderma Interstitial Lung Disease: Technical Aspects and Clinical Correlations. Sem Arthritis Rheum 2009, 40(1):73-88.

29. Atamas SP, Yurovsky W, Wise R, Wigley FM, Goter Robinson CJ, Henry P, Alms WJ, White B: Production of type 2 cytokines by CD8+ lung cells is associated with greater decline in pulmonary function in patients with systemic sclerosis. Arthritis Rheum 1999, 42(6):1168-78.

30. Vasakova M, Sterclova M, Kolesar L, Slavcev A, Pohunek P, Sulc J, Skibova J, Striz I: Bronchoalveolar lavage fluid cellular characteristics, functional parameters and cytokine and chemokine levels in interstitial lung diseases. Scand I Immunol 2009, 69(3):268-74.

doi:10.1186/1465-9921-12-22

Cite this article as: De Santis et al: $\beta$-thymosins and interstitial lung disease: study of a scleroderma cohort with a one-year follow-up. Respiratory Research 2011 12:22. 